\title{
Neuropeptide W is present in antral $G$ cells of rat, mouse, and human stomach
}

\author{
M S Mondal, H Yamaguchi, Y Date, K Toshinai, T Kawagoe, \\ T Tsuruta, H Kageyama $^{1}$, Y Kawamura ${ }^{1}$, S Shioda ${ }^{1}$, \\ Y Shimomura ${ }^{2}, \mathbf{M ~ M o r i ~}^{2}$ and M Nakazato
}

Department of Internal Medicine, Miyazaki Medical College, University of Miyazaki, Kiyotake, Miyazaki 889-1692, Japan

${ }^{1}$ Department of Anatomy, Showa University School of Medicine, Tokyo 142-8555, Japan

${ }^{2}$ Discovery Research Laboratories, Pharmaceuticals Research Division, Takeda Chemical Industries, Ibaraki 300-4293, Japan

(Requests for offprints should be addressed to M Nakazato; Email: nakazato@med.miyazaki-u.ac.jp)

\begin{abstract}
Neuropeptide W (NPW) is a 30-amino-acid peptide initially isolated from the porcine hypothalamus as an endogenous ligand for the $G$ protein-coupled receptors GPR7 and GPR8. An intracerebroventricular administration of NPW increased serum prolactin and corticosterone concentrations, decreased dark-phase feeding, raised energy expenditure, and lowered body weight. Peripherally, GPR7 receptors are abundantly expressed throughout the gastrointestinal tract; the presence of NPW in the gastrointestinal endocrine system, however, remains unstudied. Using monoclonal and polyclonal antibodies raised against rat NPW, we studied the localization of NPW in the rat, mouse, and human stomach by light and electron microscopy. NPW-immunoreactive cells were identified within the gastric antral glands in all three species. Double immunohistochemistry and electron-microscopic immunohistochemistry studies in rats demonstrated that NPW is present in antral gastrin $(G)$ cells. NPW immunoreactivity localized to round,
\end{abstract}

intermediate-to-high-density granules in G cells. NPWimmunoreactive cells accounted for $90 \%$ chromagranin A- and $85 \%$ gastrin-immunoreactive endocrine cells in the rat gastric antral glands. Using reversed-phase HPLC coupled with enzyme immunoassays specific for NPW, we detected NPW30 and its C-terminally truncated form, NPW23, in the gastric mucosa. Plasma NPW concentration of the gastric antrum was significantly higher than that of the systemic vein, suggesting that circulating NPW is derived from the stomach. Plasma NPW concentration of the gastric antrum decreased significantly after $15-\mathrm{h}$ fast and increased after refeeding. This is the first report to clarify the presence of NPW peptide in the stomachs of rats, mice, and humans. In conclusion, NPW is produced in gastric antral $G$ cells; our findings will provide clues to additional mechanisms of the regulation of gastric function by this novel brain/gut peptide.

Journal of Endocrinology (2006) 188, 49-57

\section{Introduction}

Two structurally related $G$ protein-coupled receptors (GPCRs), GPR7 and GPR8, were identified by cloning opioid-somatostatin-like receptor genes from human genomic DNA (O'Dowd et al. 1995). GPR7 and GPR8 share 70\% nucleotide and 64\% amino acid identity (O'Dowd et al. 1995). While orthologs of GPR7 and GPR 8 have been found in multiple species by PCR, a rodent GPR8 has yet to be identified (Lee et al. 1995). Rat GPR7 mRNA is widely expressed throughout the brain, including the paraventricular, supraoptic, ventromedial hypothalamic, dorsomedial hypothalamic, suprachiasmatic, and arcuate nuclei (Lee et al. 1995). This abundant GPR7 expression in the hypothalamus suggests a role in the modulation of neuroendocrine function.
Recently, we isolated an endogenous peptide ligand for GPR7 and GPR8, named neuropeptide W (NPW), from the porcine hypothalamus using a cAMP accumulation inhibition assay of Chinese hamster ovary cell lines stably expressing human GPR8 (Shimomura et al. 2002). Using the porcine cDNA sequence for prepro-NPW, we isolated swine, rat, and human cDNA fragments, indicating that NPW is highly conserved among species (Shimomura et al. 2002). Human NPW differs from the rat form by only one amino acid at position 17. Two mature NPW peptides have been identified, NPW23 and NPW30, the former corresponding to a C-terminal truncation of NPW30. NPW23 and NPW30 are produced by proteolytic processing at two pairs of arginine residues at positions 24 and 25, and 31 and 32. NPW is named after the tryptophan residues (single-letter code W) at the 
N- and C-termini of NPW30. Synthetic NPW23 and NPW30 both bind to and activate GPR7 and GPR 8 at similar effective doses. A single intracerebroventricular (icv) administration of NPW23 to rats increased serum corticosterone levels and augmented water drinking (Baker et al. 2003). We showed that icv administration of either NPW23 or NPW30 to free-feeding rats suppressed dark-phase and fasting-induced food intake at similar effective doses (Mondal et al. 2003b). Continuous icv infusion of NPW23 for 5 days using an osmotic minipump suppressed feeding and body-weight gain over the infusion period. Conversely, icv administration of antiNPW IgG increased food intake. Icv administration of NPW increased body temperature and heat production. GPR7-deficient mice are hyperphagic and develop obesity (Ishii et al. 2003). These results indicate that NPW may function as an endogenous catabolic signaling molecule in the brain.

Several gut/brain peptides exhibit diverse effects that include the regulation of feeding via the gut/brain axis in addition to gastrointestinal functions. GPR7 is robustly expressed in various peripheral tissues of rats, including the stomach and intestine (Fuji et al. 2002). NPW mRNA is expressed in the stomach, but a cellular source has yet to be identified (Tanaka et al. 2003). In this study, we investigated the cellular source of NPW in the rat, mouse, and human stomach by immunohistochemistry, immunohistochemical double-staining, and immunoelectron microscopy. Characterization of the NPW molecular forms present in the stomach was performed by reversed-phase HPLC (RP-HPLC) coupled with enzyme immunoassay (EIA). We determined plasma NPW concentrations in the gastric antral vein and systemic vein. Finally, we studied the effects of fasting and high-lipid diet and highcarbohydrate diet on plasma NPW concentration. Here, we report that the NPW-producing cells are the gastrin (G) cells in the gastric antrum.

\section{Materials and Methods}

\section{Animals}

Male Wistar rats, weighing 250-300 g (Charles River Japan, Shiga, Japan), were used in all the experiments. Animals were given standard laboratory chow and water ad libitum. All procedures were performed in accordance with the Japanese Physiological Society's guidelines for animal care. The experimental protocol was approved by the Ethics Review Committee for Animal Experimentation of the Miyazaki Medical College, University of Miyazaki.

\section{Peptide synthesis}

Human NPW23 and NPW30, rat NPW23 and NPW30, human $\left[{ }^{14} \mathrm{Cys}\right] \mathrm{NPW}-[1-13]$, human $\left[{ }^{1} \mathrm{Cys}\right] \mathrm{NPW}-[11-23]$,

\section{1 \\ 2023 \\ 30 \\ Human NPW WYKHVASPRYHTVGRAAGLIMGLRRSPYLW \\ Rat NPW}

Figure 1 Alignment of the amino acid sequences of human and rat NPW. Numbers indicate amino acid positions from the $\mathrm{N}$-terminus. Dashed lines indicate same amino acids.

and rat $\left[{ }^{1} \mathrm{Cys}\right] \mathrm{NPW}-[16-30]$ were synthesized using an ABI 433A peptide synthesizer (Applied Biosystems, Foster City, CA, USA) following an Fmoc ( $N$-(9-fluorenyl)methoxycarbonyl) strategy. Amino acid sequences of human and rat NPW are shown in Fig. 1. After de-blocking all the protecting groups by treatment with a mixture of trifluoroacetic acid (TFA)/thioanisole/ $m$-cresol/tri-isopropylsilane/1,2ethane-dithiol $(85: 5: 5: 2 \cdot 5: 2 \cdot 5)$, peptides were purified by RP-HPLC. Cys-extended peptides were used for the immunizations described below. The validity of the synthesis was confirmed by amino acid analysis, sequencing, and spectrometric analysis.

\section{Preparation and characterization of antisera}

To obtain monoclonal antibodies recognizing the $\mathrm{N}$-terminal region of NPW, the C-terminal region of NPW23, and the C-terminal region of NPW30, we conjugated human $\left[{ }^{14} \mathrm{Cys}\right] \mathrm{NPW}-[1-13]$ and human $\left[{ }^{1} \mathrm{Cys}\right] \mathrm{NPW}-[11-23]$ with porcine thyroglobulin and rat $\left[{ }^{1} \mathrm{Cys}\right] \mathrm{NPW}-[16-30]$ to keyhole limpet hemocyanin using sulfosuccinimidyl 4-(N-maleimidomethyl) cyclohexane-1 carboxylate (Sulfo-SMCC; Pierce Chemical Co., Rockford, IL, USA). BALB/c mice (female, 6-8 weeks old) were immunized with each immunogen. The spleen cells isolated from the immunized mice 3 days after intravenous immunogen injection were fused with mouse myeloma cells, P3X63Ag8.653, as described previously (Suzuki et al. 1989). Three monoclonal antibodies, ANPW-N $(\operatorname{IgG1}, \kappa)$ for the N-terminal region of NPW, ANPW23-C (IgG1, $\kappa)$ for the C-terminal region of NPW23, and ANPW30-C (IgG2b, $\kappa)$ for the C-terminal region of NPW30, were purified from ascites fluids using an immobilized protein A column (Seikagaku Co., Tokyo, Japan). To raise polyclonal anti-NPW antisera, synthetic human $\left[{ }^{14} \mathrm{Cys}\right] \mathrm{NPW}-[1-13]$ was conjugated to maleimide-activated mariculture keyhole limpet hemocyanin (Sulfo-SMCC). The antigenic conjugate solution $(1.5-3 \mathrm{ml})$ was administered to New Zealand white rabbits. The resulting rabbit antihuman NPW-[1-13] antiserum recognized both human NPW23 and NPW30. The antisera exhibited 100\% cross-reactivity with rat NPW23 and NPW30.

\section{EIA procedure for NPW23 and NPW30}

The ANPW23-C and ANPW30-C antibodies were immobilized to $96-$ well microtest plates. ANPW-N was 
conjugated to horseradish peroxidase (HRP) as described previously (Ichimori et al. 1987); the HRP-labeled ANPW-N was used to detect NPW23 and NPW30 trapped by immobilized antibody. The two-site EIA for NPW was performed essentially as described by Ichimori et al. (1987) with the following minor modification. The immobilized antibody plates were prepared by adding $20 \mu \mathrm{g} / \mathrm{ml}$ of either ANPW23-C or ANPW30-C followed by $300 \mu \mathrm{l}$ Block Ace (Snow Brand Milk Products Co., Sapporo, Japan). Rat NPW23 and NPW30 standard peptides or unknown test samples in $100 \mu$ l buffer $\mathrm{C}$ (20 mM phosphate buffer $(\mathrm{pH} 7 \cdot 0), 1 \%$ BSA, $0.4 \mathrm{M}$ $\mathrm{NaCl}$, and $2 \mathrm{mM}$ EDTA) were added to the antibodyimmobilized plates and incubated at $4{ }^{\circ} \mathrm{C}$ for $16 \mathrm{~h}$. After washing with PBS, plates were treated with $100 \mu \mathrm{HRP}-$ labeled ANPW-N at a 1000-fold dilution in buffer C at $4{ }^{\circ} \mathrm{C}$ for an additional $16 \mathrm{~h}$. After washing with PBS, bound enzyme activity was measured using a TMB microwell peroxidase system (Kirkegaard and Perry Laboratories, Gaithersburg, MD, USA).

\section{Reverse transcription PCR (RT-PCR) for NPW}

Total RNA was extracted from the mucosal and muscular layers of antral stomachs of three Wistar rats using the acid guanidinium thiocyanate/phenol/chloroform (AGPC) method (Chomczynski \& Sacchi 1987). First-strand cDNA was synthesized from $2.5 \mu \mathrm{g}$ RNA with $7 \mu \mathrm{M}$ oligo-(dT) 18 primer and ReverTra Ace- $\alpha-{ }^{\text {- }}{ }^{\circ}$ reverse transcriptase (Toyobo Co., Osaka, Japan). The resulting cDNA was subjected to PCR amplification using $2 \mu \mathrm{M}$ of each sense and antisense primer and 2.5 units Pyrobest DNA polymerase (Takara Shuzo Co., Shiga, Japan). PCR primers for NPW were 5'-CCAACCTGAGCAGTCG CTAAG-3' (sense) and 5'-TCGGTTCTTGAGACGGT CGT-3' (antisense), corresponding to nucleotide numbers $486-506$ and $636-655$ (Shimomura et al. 2002). PCR was conducted in a $25 \mu \mathrm{l}$ reaction volume for 35 cycles, comprising denaturation for $5 \mathrm{~s}$ at $94{ }^{\circ} \mathrm{C}$, annealing for $10 \mathrm{~s}$ at $65^{\circ} \mathrm{C}$, and extension for $1 \mathrm{~min}$ at $72^{\circ} \mathrm{C}$. PCR products were electrophoresed on a $2 \%$ agarose gel (FMC BioProducts, Rockland, ME, USA).

\section{Quantification of immunoreactive NPW in rat stomach}

Immediately after decapitation, stomachs were resected from ten 12-week-old male Wistar rats fed ad libitum. The whole gastric antrum and the mucosal layer from the glandular part of the stomach were removed from five and ten rats, respectively. Tissues were heated at $95-100{ }^{\circ} \mathrm{C}$ for $10 \mathrm{~min}$ in a 10 -fold volume of water to inactivate intrinsic proteases. After cooling to $4{ }^{\circ} \mathrm{C}$, ethanoic acid and $\mathrm{HCl}$ were added to final concentrations of $1 \mathrm{M}$ and $20 \mathrm{mM}$, respectively. The tissues were then homogenized in a Polytron for $10 \mathrm{~min}$. Homogenates were centrifuged at $11500 \mathrm{~g}$ for $30 \mathrm{~min}$. After applying the supernatants to Sep-Pak C-18 cartridges (Waters, Milford, MA, USA), bound peptides were eluted in $60 \%$ acetonitrile containing $0 \cdot 1 \%$ TFA. The antrum eluates were quantified by EIAs for NPW23 and NPW30. Some portions of the stomach mucosa eluates were quantified by two EIAs, while the remaining portions were subjected to RP-HPLC. All HPLC fractions were quantified by EIAs. Authentic rat NPW23 and NPW30 were chromatographed by the same HPLC system.

Quantification of plasma NPW in the gastric antral vein and systemic vein, after a $15 \mathrm{~h}$ fast

For the determination of NPW30 concentration in the systemic vein and gastric antral vein, three groups of rats which had been fed ad libitum $(n=9)$, fasted for $15 \mathrm{~h}$ from 19:00 to the next morning at 10:00 $(n=9)$ or fasted for $15 \mathrm{~h} \mathrm{(19:00-10:00)}$ and then refed for $2 \mathrm{~h}(n=9)$ were studied. The stomach was exposed after anesthesia with sodium pentobarbital. The gastroesophageal and the gastroduodenal junctures were ligated by grade $4 \cdot 0$ silk. Blood was obtained from the gastric antral vein. Since the plasma volume obtained from the gastric antrum of one rat was $30 \mu$, plasma samples from three rats were pooled for the determination of NPW. The plasma of the jugular vein was obtained from the same rats. The plasma samples were diluted $1: 1$ with $0.9 \%$ saline and applied to Sep-Pak C-18 cartridges pre-equilibrated with $0.9 \%$ saline. The adsorbed peptides were eluted with a $60 \%$ acetonitrile solution containing $0 \cdot 1 \%$ TFA, and then subjected to EIA for NPW30.

\section{Effects high-lipid diet and high-carbohydrate diet on plasma} NPW concentration

Rats were first fed standard laboratory diets for 7 days. They next were given high-lipid diet $(40 \cdot 1 \% \mathrm{kcal}$ derived from carbohydrate, $34.7 \% \mathrm{kcal}$ derived from fat, and $25 \cdot 2 \%$ derived from protein; KBT Oriental Co., Saga, Japan) or high-carbohydrate diet $(65 \cdot 2 \% \mathrm{kcal}$ derived from carbohydrates, $9 \cdot 6 \% \mathrm{kcal}$ derived from fat, and $25 \cdot 2 \% \mathrm{kcal}$ derived from protein; $n=7$ per group) for 2 weeks. Plasma samples from the gastric antral vein of rats fed ad libitum were pooled and then subjected to EIA for NPW30.

\section{Light-microscopic immunostaining}

Three Wistar rats were anesthetized by intraperitoneal injection of sodium pentobarbital $(75 \mathrm{mg} / \mathrm{kg}$ body weight). Animals were then perfused transcardially for $10 \mathrm{~min}$ with $100 \mathrm{ml} 0 \cdot 1 \mathrm{M}$ phosphate buffer $(\mathrm{pH} 7 \cdot 4$ ) containing heparin $(100 \mathrm{U} / 100 \mathrm{ml})$, then for an additional $15 \mathrm{~min}$ with $150 \mathrm{ml}$ fixative containing 4\% paraformaldehyde. After removal, rat stomachs were postfixed with 
fixative for $24 \mathrm{~h}$ at $4{ }^{\circ} \mathrm{C}$, and then incubated for $24 \mathrm{~h}$ in $0 \cdot 1$ M PBS (pH 7.4) containing 30\% sucrose. Glandular stomachs were quickly frozen in dry ice and stored at $-80{ }^{\circ} \mathrm{C}$. Mouse gastric antrums $(n=3)$ were obtained from C57B6/J mice. Human gastric antrums were obtained at autopsy from three patients who had died of cardiovascular disease. Written consent from the deceased relatives was taken prior to the removal of tissues and the study was approved by the Ethics Committee of Human Research of Miyazaki Medical College. Samples were cut serially at $-20{ }^{\circ} \mathrm{C}$ with a cryostat into slices $7 \mu \mathrm{m}$ thick, then thaw-mounted on silane-coated slides and stored at $-80{ }^{\circ} \mathrm{C}$. Serial sections were treated with $0 \cdot 3 \%$ hydrogen peroxide to inactivate endogenous peroxidase activity, and then incubated with normal goat serum to block non-specific binding. These sections were incubated overnight at $4{ }^{\circ} \mathrm{C}$ with anti-NPW-[1-13] antiserum (final dilution 1:5000), anti-NPW antiserum (ANPW-N; final dilution 1:5000), anti-chromogranin $\mathrm{A}$ antiserum (DAKO Corp., Glostrup, Denmark; final dilution 1:500), antigastrin antiserum (DAKO Corp.; final dilution 1:5), anti-somatostatin antiserum (DAKO Corp.; final dilution 1:200), or anti-serotonin antiserum (DAKO Corp.; final dilution 1:5). All sections were stained using the avidinbiotin complex method described previously (Date et al. 2000). We examined three immunostained slides for analytical purposes. Control studies were done with normal rabbit serum or anti-NPW-[1-13] antiserum that had been pre-absorbed with $10 \mu \mathrm{g}$ rat NPW.

\section{Electron-microscopic immunohistochemistry}

Three Wistar rats were perfused with $2 \%$ paraformaldehyde and $2 \cdot 5 \%$ glutaraldehyde in $0 \cdot 1 \mathrm{M}$ PBS. Electron microscopy imunnohistochemistry was performed as described previously (Date et al. 2000) with minor modifications. Stomachs were excised and fixed with the above fixative overnight at $4{ }^{\circ} \mathrm{C}$, then postfixed at $4{ }^{\circ} \mathrm{C}$ for 90 min with $1 \%$ osmium tetroxide in $0.1 \mathrm{M}$ PBS. Samples were then dehydrated using a graded ethanol series and embedded in Epon. Ultrathin sections of the specimens were cut and treated for 30 min with 5\% sodium metaperiodate. Samples were immersed for $10 \mathrm{~min}$ in $5 \%$ normal goat serum in PBS supplemented with $1 \%$ BSA, then incubated overnight at $4{ }^{\circ} \mathrm{C}$ with rabbit polyclonal anti-NPW-[1-13] antiserum (dilution 1:5000). Next, sections were incubated with $8 \mathrm{~nm}$ colloidal goldconjugated anti-rabbit goat IgG (Jackson British Bio Cell International, Cardiff, UK; dilution 1:50) and counterstained with uranyl acetate and lead citrate. As controls, anti-NPW antiserum was either omitted or replaced by normal rabbit serum. Sections were examined using an Hitachi H-7000 electron microscope (Ibaraki, Japan). The size of $200 \mathrm{NPW}$-containing granules was measured.

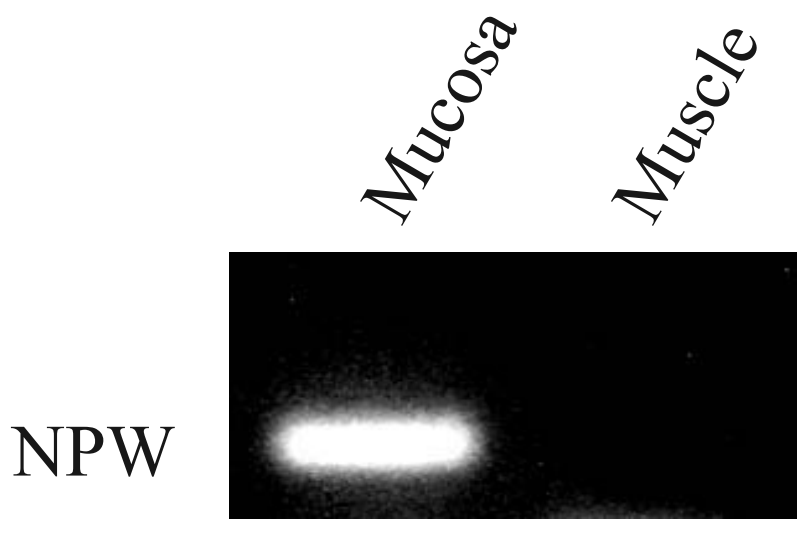

Figure 2 Representative agarose gel showing the RT-PCR product corresponding to NPW mRNA amplified from the mucosal layer of the rat gastric antrum.

\section{Results}

\section{RT-PCR amplification of NPW transcript}

Using NPW-specific primers, we amplified an RT-PCR product corresponding to the predicted size of the NPW transcript (347 bp) from an RNA sample derived from the mucosal layer of the rat stomach, but did not detect it in the sample from the muscle layer (Fig. 2).

\section{Identification of NPW molecules and NPW level in rat gastric antrum}

RP-HPLC, coupled with two separate EIAs, was used to analyze NPW molecules from the rat gastric mucosa (Fig. 3). In the EIA for NPW23 we detected one major peak,

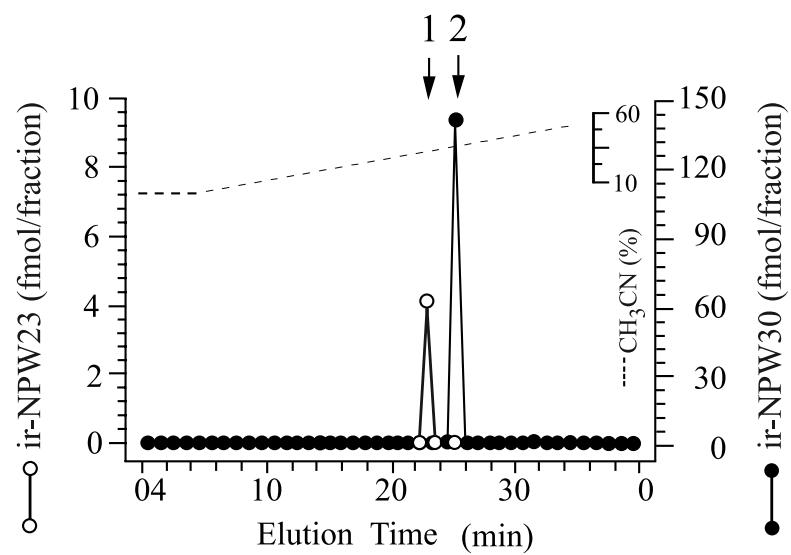

Figure 3 Representative RP-HPLC profile of NPW23 and NPW30 immunoreactivities in rat stomach. Gastric mucosa (50 mg) was subjected to chromatography on a TSK ODS SIL $120 \mathrm{~A}$ column $(4.6 \times 150 \mathrm{~mm})$. RP-HPLC was performed for $40 \mathrm{~min}$ at $1.0 \mathrm{ml} / \mathrm{min}$ with a linear gradient of $10-60 \%$ acetonitrile $\left(\mathrm{CH}_{3} \mathrm{CN}\right)$ containing $0 \cdot 1 \%$ TFA. Arrows indicate the elution positions of authentic NPW23 (1) and NPW30 (2). NPW23 and NPW30 values are represented by the left and right scales, respectively. 


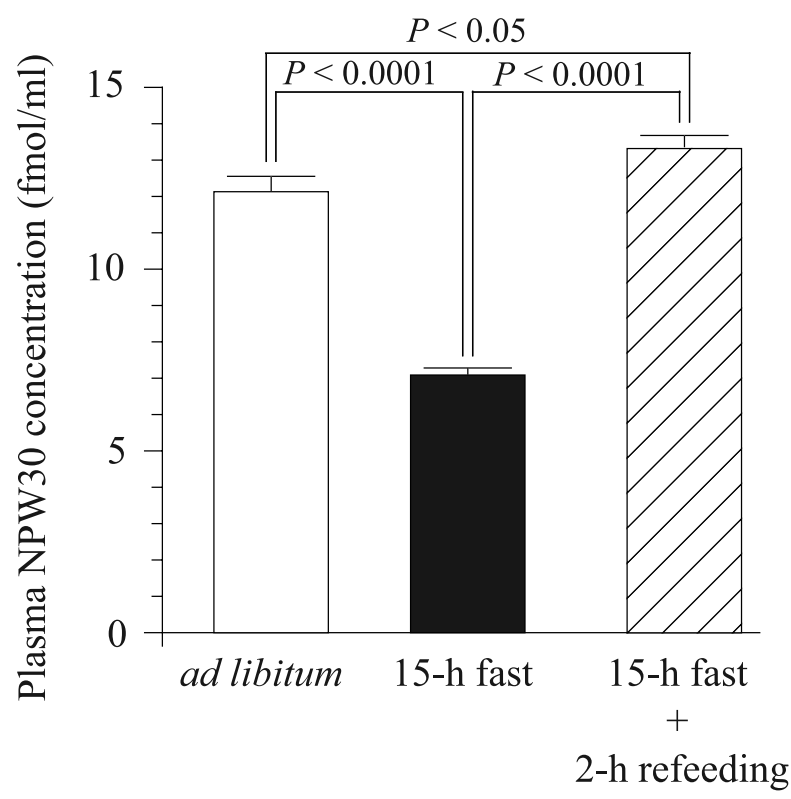

Figure 4 Plasma NPW30 concentrations in the gastric antrum in rats fed ad libitum, fasted for $15 \mathrm{~h}$, or fasted for $15 \mathrm{~h}$ and then fed for $2 \mathrm{~h}$. eluting at a position consistent with authentic NPW23 (peak 1). EIA for NPW30 also revealed one major NPW-immunoreactive peak eluting at position consistent with authentic NPW30 (peak 2). Respective contents of NPW23 and NPW30 in the rat gastric antrum were $32 \cdot 3 \pm 0.8$ and $142 \cdot 7 \pm 14.7 \mathrm{fmol} / \mathrm{g}$ tissue weight (means \pm S.E., $n=3$ ).

\section{Plasma NPW concentrations after 15-h fast and high-lipid} and high-carbohydrate diet

The plasma concentration of NPW30 in the gastric antral vein in rats fed ad libitum was $12 \cdot 0 \pm 0 \cdot 4 \mathrm{fmol} / \mathrm{ml}$ and that in the systemic vein $0 \cdot 42 \pm 0 \cdot 7 \mathrm{fmol} / \mathrm{ml}$. Plasma NPW30 concentration of the gastric antrum decreased significantly after fast and increased upon refeeding (Fig. 4). No significant difference in plasma NPW30 concentration of the gastric antrum was observed between rats fed with high-lipid diet and with high-carbohydrate diet for 2 weeks (high-fat, $9 \cdot 6 \mathrm{fmol} / \mathrm{ml}$, versus high-carbohydrate, $9 \cdot 7 \mathrm{fmol} / \mathrm{ml})$.
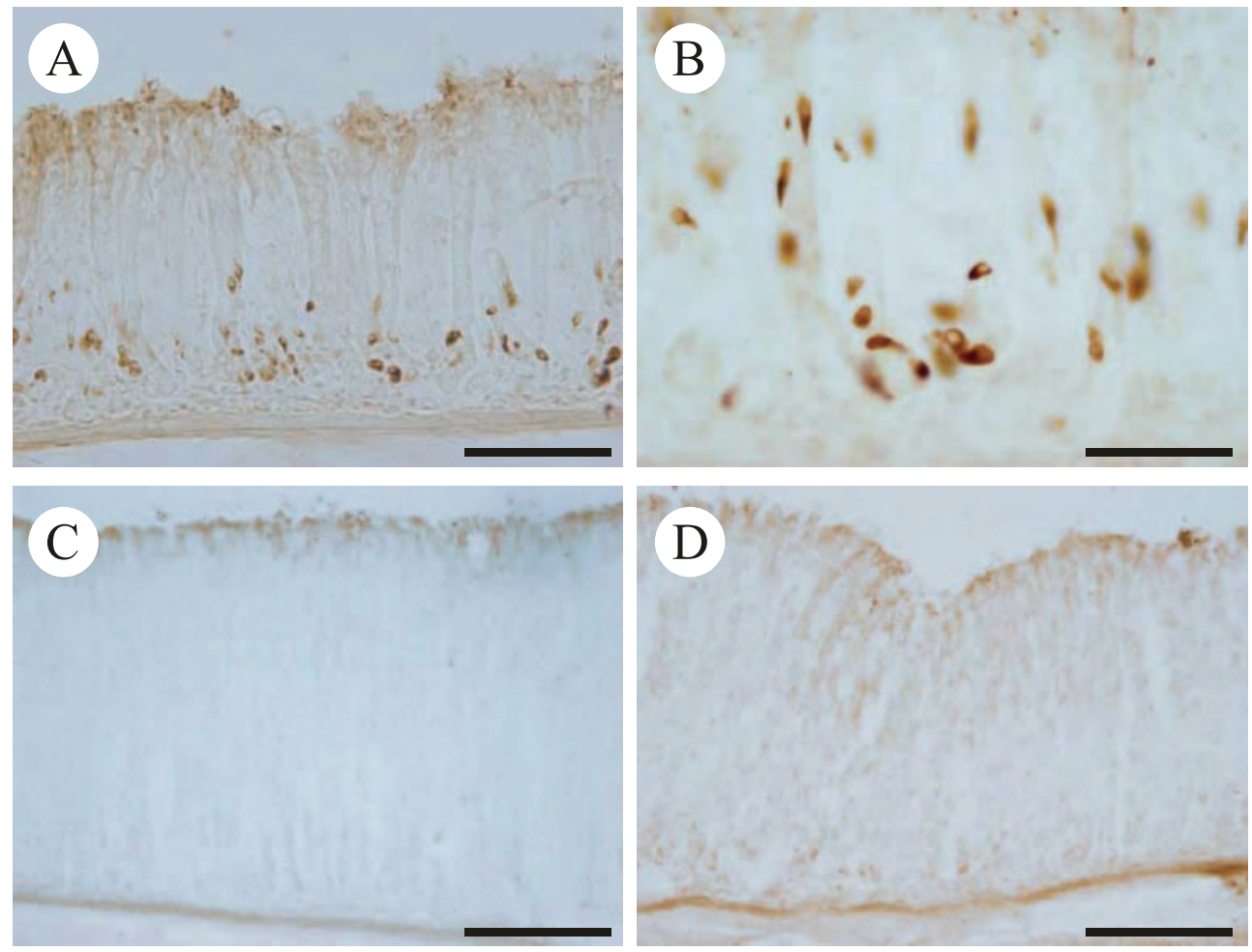

Figure 5 Immunohistochemical localization of NPW in the rat stomach. (A) NPW-immunoreactive cells in the gastric antrum. Scale bar, $100 \mu \mathrm{m}$. (B) Higher magnification of NPW cells. Scale bar, $50 \mu \mathrm{m}$. (C) No NPW-immunoreactive cells in the gastric fundus. (D) Absorption test. (C, D) Scale bars, $100 \mu \mathrm{m}$. 

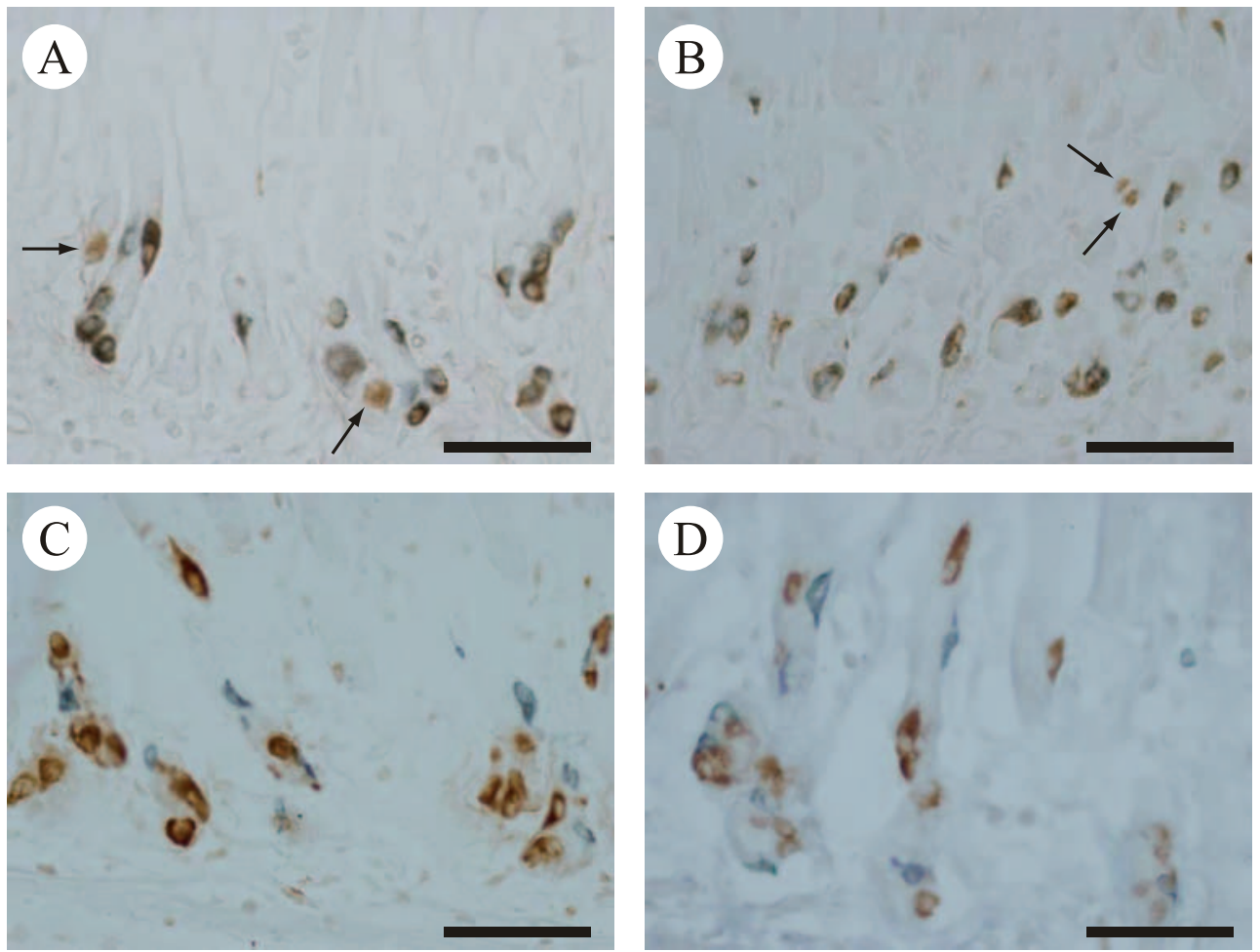

Figure 6 Immunohistochemical localization of NPW in the rat gastric antrum. NPW (blue-black in A and B; brown in $\mathrm{C}$ and $\mathrm{D}$ ) co-localizes with (A) chromogranin $\mathrm{A}$ (brown) and (B) gastrin (brown), but not with (C) somatostatin (blue-black) or (D) serotonin (blue-black). The majority of (A) chromogranin A cells and (B) G cells have NPW immunoreactivity, whereas some chromogranin A cells and G cells do not have it, as indicated by the arrows. Scale bars, $50 \mu \mathrm{m}$.

\section{Immunohistochemistry}

NPW-immunoreactive cells were scattered throughout the mucosal layer of rat gastric antrum (Fig. 5A and B). NPW cells were present in the basal part of the mucosal layer. No NPW-positive cells, however, could be detected in the gastric fundus (Fig. 5C). No specific immunoreactivity was observed in the rat gastric antrum when either normal rabbit serum or antiserum pre-absorbed with excess NPW was used (Fig. 5D). Double staining of NPW-immunoreactive cells in the rat gastric antrum is shown in Fig. 6. NPW-immunoreactive cells accounted for $90 \%$ (90 of 100) of chromogranin A-immunoreactive cells (Fig. 6A) and for 85\% (85 of 100) of gastrinimmunoreactive endocrine cells (Fig. 6B), but did not have somatostatin or serotonin immunoreactivity (Fig. 6C and D). NPW immunoreactivity was also present in the mouse gastric antrum (Fig. 7A and B). NPWimmunoreactive cells were abundant in the middle layer of the mucosa of the human antral glands (Fig. 7C). NPW immunoreactivity was found in $89 \%$ (89 of 100) of human antral G cells (Fig. 7D). No specific immunoreactivity was observed in the mouse or human gastric antrum when normal rabbit serum or antisera pre-absorbed with excessive NPW was used (data not shown).

\section{Immunoelectron microscopy}

Immunoelectron microscopy showed the typical morphology of granules in rat antral G cells (Fig. 8A). Immunogold particles indicative of NPW immunoreactivity were observed in multiple, round, intermediateto-high-density granules (Fig. 8B). The storage granules were clustered at the cell base and $189 \pm 14 \mathrm{~nm}$ (mean \pm S.E.) in diameter.

\section{Discussion}

Using cell-based reporter systems, searches for endogenous ligand for orphan GPCRs have led to the discovery of multiple novel peptides (Kalra et al. 1999, Schwartz et al. 2000, Spiegelman \& Flier 2001, Ahima \& Osei 2001). NPW was isolated from the porcine hypothalamus as a peptide ligand for the heretofore called 'orphan' 

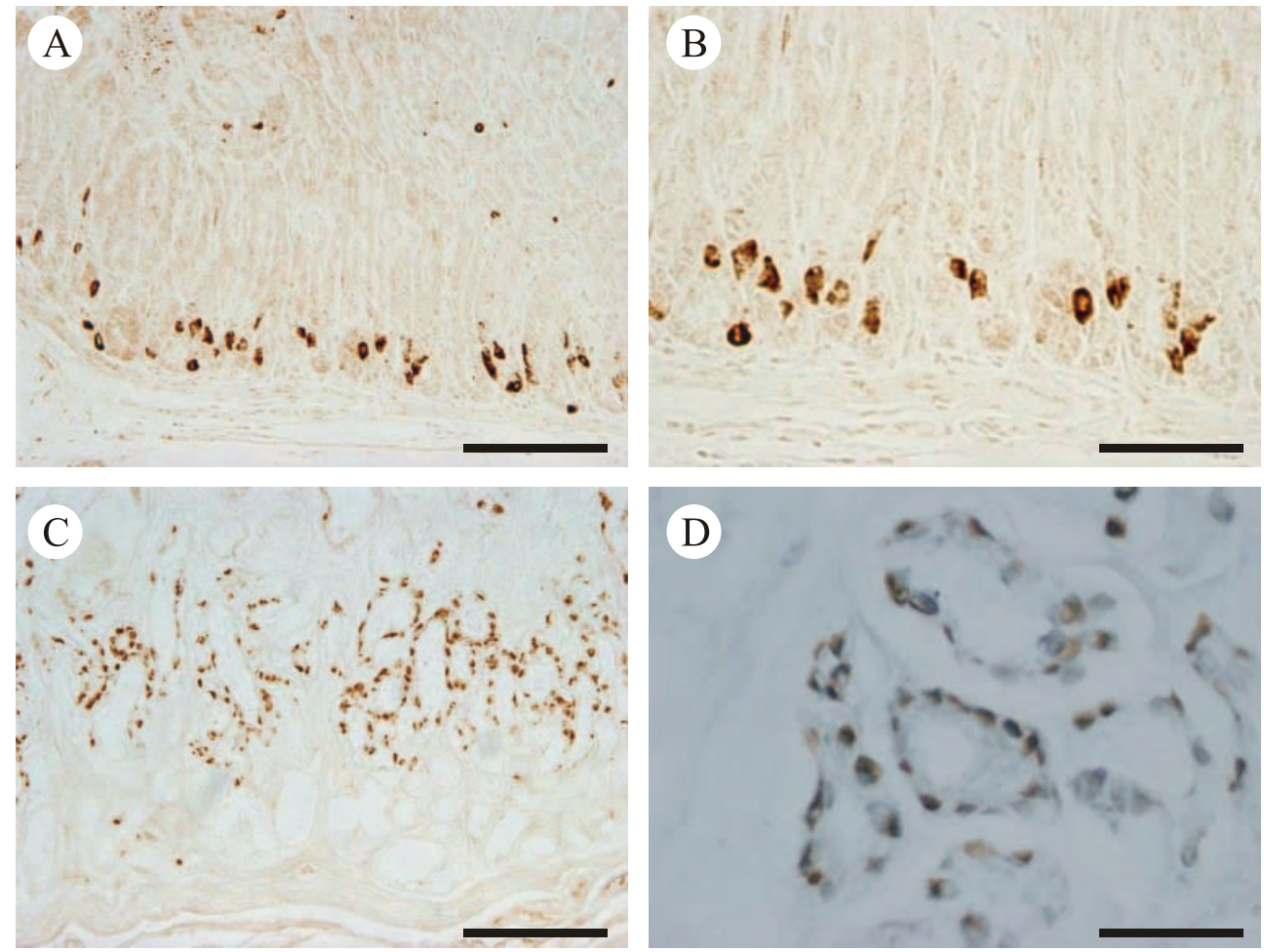

Figure 7 Immunohistochemical localization of NPW in the mouse and human gastric antrum.

(A) NPW-immunoreactive cells in mouse gastric antrum. Scale bar, $100 \mu \mathrm{m}$. (B) Higher magnification of (A). Scale bar, $50 \mu \mathrm{m}$. (C) NPW-immunoreactive cells in human gastric antrum. Scale bar, $100 \mu \mathrm{m}$. (D) NPW (blue-black) co-localizes with gastrin (brown) in human antrum. Scale bar, $50 \mu \mathrm{m}$.

GPCRs, GPR7 and GPR8, using this application system (Shimomura et al. 2002). Two mature endogenous molecular forms of NPW, NPW23 and NPW30, were identified (Shimomura et al. 2002). Central administration of NPW suppressed dark-phase and fasting-induced feeding, increased energy expenditure, and augmented serum prolactin and corticosterone (Baker et al. 2003, Mondal et al. 2003b). Chronic administration of NPW decreased food intake and caused weight loss (Mondal et al. 2003b). These findings suggest that NPW may play a role in feeding behavior and energy homeostasis. Gut/brain peptides involved in the regulation of feeding behavior, such as somatostatin, cholecystokinin, orexin-A, neuromedin $U$, and ghrelin, also contribute to the regulation of gastric acid secretion, gastric mucosal cell proliferation, and neural regulation of the enteric nervous system (Polak et al. 1975a, 1975b, Moran and McHugh 1982, Aponte et al. 1984, Sakurai et al. 1998, Kirchgessner \& Liu 1999, Date et al. 2000, Nakazato et al. 2001, Wren et al. 2002, Mondal et al. 2003a). Rat GPR7 mRNA is expressed in the stomach and intestine (Tanaka et al. 2003), but the presence of NPW in the gastrointestinal tract has yet to be identified. Our RT-PCR analysis revealed that NPW mRNA is present in the rat gastric antrum. Using the combination of two EIAs with HPLC, we first detected
NPW23 and NPW30 in the rat stomach mucosa. Our present study showed that the plasma NPW concentration of the gastric antrum was higher than that of the systemic vein, suggesting that circulating NPW is derived from the stomach. Plasma NPW concentration did not change after high-lipid diet or high-carbohydrate diet, suggesting that dietary nutrients do not influence NPW secretion from the gastric antrum. Plasma NPW concentration of the gastric antrum decreased upon fast and increased after refeeding. An icv administration of NPW to rats decreased food intake and body-weight gain (Mondal et al. 2003b). Further investigations are needed to clarify the functional relationship between central and peripheral NPW in the regulation of feeding.

We identified NPW-immunoreactive endocrine cells in the rat, mouse, and human stomachs. NPWimmunoreactive cells are abundant in the mucosal layer of the antrum in these three species. The antral mucosa has roughly equal numbers of three endocrine cell types - G cells, enterochromaffin cells (EC), and somatostatin (D) cells - which respectively secrete gastrin, serotonin, and somatostatin (Solcia et al. 1987, Walsh 1994). We showed that $85 \%$ of NPW-immunoreactive cells were identifiable as antral $\mathrm{G}$ cells. $\mathrm{G}$ cells are most abundant in the rat gastric antrum mucosa where they may number $5 \times 10^{5} / \mathrm{cm}^{2}$ 

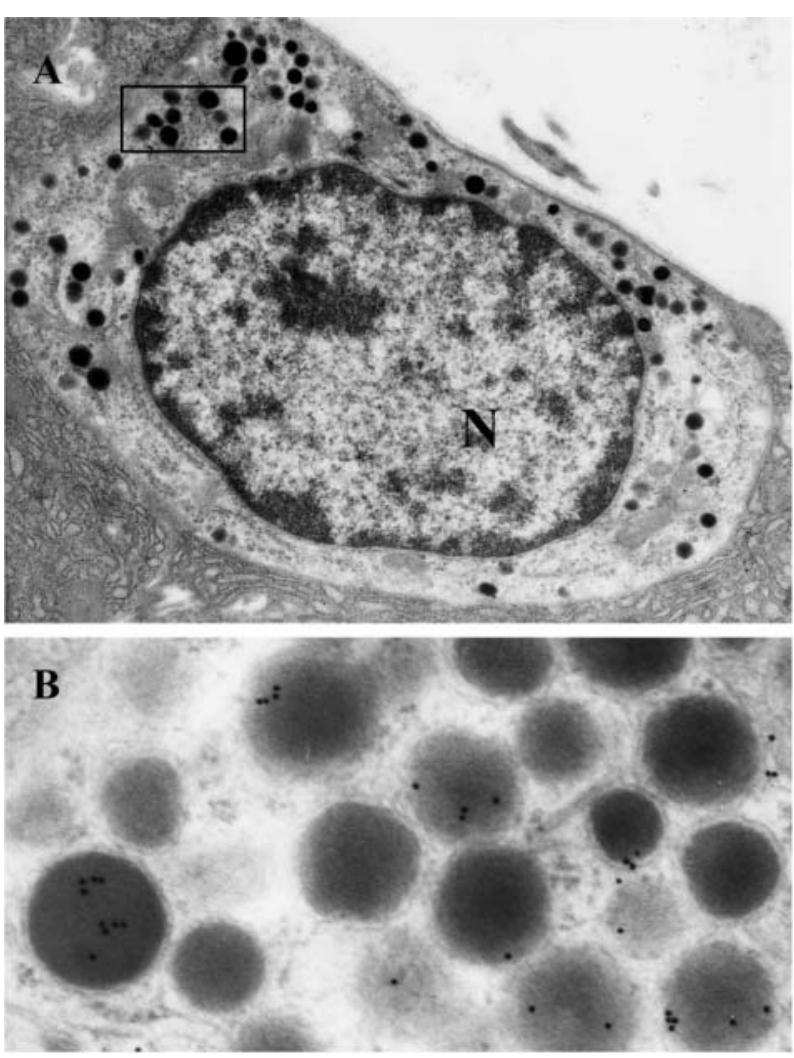

Figure 8 Representative immunoelectron micrographs of NPW cells in rat gastric antral gland. (A) The antral gastrin $G$ cell contains multiple, round, intermediate-to-high-density granules. N, nucleus. Scale bar, $0.5 \mu \mathrm{m}$ (original magnification $\times 7000$ ). (B) Higher magnification of (A). Granules in the cytoplasm are labeled with immunogold staining for NPW. Scale bar, $100 \mathrm{~nm}$ (original magnification $\times 36000$ )

(Fawcett 1994). The G cells are flask-shaped cells with a varying distribution throughout the mucosal levels of different species (Solcia et al. 1987). We observed that G cells predominate in the basal part of the mucosal glands in rats, and in contrast they are found in the middle layer of the mucosa in humans. This study showed that NPW immunoreactivity is present in multiple, round, intermediate-to-high-density granules within G cells. G cells express an impressive number of peptides, including polypeptide $\mathrm{Y}$, neurotensin, vasointestinal peptide, ACTH, thyrotropin-releasing hormone, pro-enkephalingene-derived peptides, xenopsin, and human chorionic gonadatrophin $\alpha$ (Sundler \& Håkanson 1991, Capella et al. 1991). The physiological significance of expression of many peptides in $\mathrm{G}$ cells is presently less well understood. The functional significance of co-expression of NPW with gastrin is unclarified.

In our on-going study, one finding showed that an intraperitoneal administration of NPW to rats increased the gastric acid secretion. Additional studies would be necessary to determine the role of NPW in the regulation of motility of the gut wall, gastric acid secretion, and the renewal of the gut epithelium.

G cells, which also have NPW, belong to the 'open' type cells which have apical cytoplasmic extensions that project to the glandular lumen with short microvilli and pinocytotic vesicles (Fujita \& Kobayashi 1977). This structure is regarded as representing the anatomical basis for the cell response to physical and/or chemical variations of the gastric contents. The secretory granules in 'open' type cells usually exhibit clear-cut polarization in the basal cytoplasmic pole or in basal cytoplasmic processes. NPWcontaining granules are clustered at the cell base. In response to vagal stimulation or distension of the stomach, $\mathrm{G}$ cells secrete gastrin, a peptide hormone that stimulates gastric motility and acid secretion from the oxyntic cells. Gastrin also acts on the stem cells in the gastric glands to stimulate cell proliferation and differentiation. NPW30 was found in the gastric vein circulation. Identification of NPW immunoreactivity within G cells suggests a feasible mechanism for delivering NPW to other tissues that express GPR7. The morphological features of NPWimmunoreactive cells suggest that NPW may function in an endocrine fashion.

Future determination of NPW peptide and mRNA contents in the stomach under various physiological and pathophysiological conditions should provide additional information concerning the mechanisms by which the biosynthesis and secretion of this peptide are governed. The findings presented here will help establish new ways to clarify the additional, as yet undefined, physiological functions of this novel brain/gut hormone, NPW.

\section{Acknowledgements}

This study was supported in part by the 21st Century COE Program and grants-in-aid from the Ministry of Education, Culture, Sports, Science, and Technology of Japan; the Ministry of Health, Labor, and Welfare of Japan; Takeda Medical Research Foundation; Meiji Yasuda Life Foundation of Health and Welfare; the Fujisawa Foundation; The Naito Foundation; Program for Strategic Regional Science and Technology Advancement to $\mathrm{M} \mathrm{N}$. The authors declare that there is no conflict of interest that would prejudice the impartiality of this scientific work.

\section{References}

Ahima RS \& Osei SY 2001 Molecular regulation of eating behavior: new insights and prospects for therapeutic strategies. Trends in Molecular Medicine 7 205-213.

Aponte G, Leung P, Gross D \& Yamada T 1984 Effects of somatostatin on food intake in rats. Life Sciences $35741-746$. 
Baker JR, Cardinal K, Bober C, Taylor MM \& Samson WK 2003 Neuropeptide W acts in brain to control prolactin, corticosterone, and growth hormone release. Endocrinology 144 2816-2821.

Capella C, Finzi G, Cornaggia M, Usellini L, Luinetti O, Buffa R \& Solcia E 1991 Ultrastructural typing of gastric endocrine cells. In The Stomach as an Endocrine Organ, pp 27-51. Eds R Håkanson \& F Sundler. Amsterdam: Elsevier.

Chomczynski P \& Sacchi N 1987 Single-step method of RNA isolation by acid guanidinium thiocyanate-phenol-chloroform extraction. Annals of Biochemistry 162 156-159.

Date Y, Kojima M, Hosoda H, Sawaguchi A, Mondal MS, Suganuma T, Matsukura S, Kangawa K \& Nakazato M 2000 Ghrelin, a novel growth hormone-releasing acylated peptide, is synthesized in a distinct endocrine cell type in the gastrointestinal tracts of rats and humans. Endocrinology 141 4255-4261.

Fawcett DW 1994 The esophagus and stomach. In A Textbook of Histology, pp 606-615. Eds W Bloom \& DW Fawcett. New York: Chapman and Hall.

Fuji R, Yoshida H, Fukusumi S, Habata Y, Hosoya M, Kawamata Y, Yano T, Hinuma S, Kitada C, Asami T et al. 2002 Identification of a neuropeptide modified with bromine as an endogenous ligand for GPR7. Journal of Biological Chemistry 277 34010-34016.

Fujita T \& Kobayashi S 1977 Structure and function of gut endocrine cells. International Review of Cytology 6 187-233.

Ichimori Y, Suzuki N, Kitada C \& Tsukamoto K 1987 Monoclonal antibodies to human interferon-gamma. II: Antibodies with neutralizing activity. Hybridoma 6 173-181.

Ishii M, Fei H \& Friedman JM 2003 Targeted disruption of GPR7, the endogenous receptor for neuropeptide $\mathrm{B}$ and $\mathrm{W}$, leads to metabolic defects and adult-onset obesity. PNAS $\mathbf{1 0 0}$ 10540-10545.

Kalra SP, Dube MG, Pu S, Xu B, Horvath TL \& Kalra PS 1999 Interacting appetite-regulating pathways in the hypothalamic regulation of body weight. Endocrine Reviews 20 68-100.

Kirchgessner AL \& Liu M 1999 Orexin synthesis and response in the gut. Neuron 24 941-951.

Lee DK, Nguyen T, Porter CA, Cheng R, George SR \& O'Dowd BF 1995 Two related G protein-coupled receptors: the distribution of GPR7 in rat brain and the absence of GPR 8 in rodents. Molecular Brain Research 71 96-103.

Mondal MS, Date Y, Murakami N, Toshinai K, Shimbara T, Kangawa K \& Nakazato M 2003 a Neuromedin U acts in the central nervous system to inhibit gastric acid secretion via CRH system. American Journal of Physiology Gastrointestinal and Liver Physiology 284 G963-G969.

Mondal MS, Yamaguchi H, Date Y, Shimbara T, Toshinai K, Shimomura Y, Mori M \& Nakazato M 2003b A role for neuropeptide $\mathrm{W}$ in the regulation of feeding behavior. Endocrinology 144 4729-4733.

Moran TH \& McHugh PR 1982 Cholecystokinin suppresses food intake by inhibiting gastric emptying. American Journal of Physiology Regulatory Integrative and Comparative Physiology 242 R491-R497.

Nakazato M, Murakami N, Date Y, Kojima M, Matsuo H, Kangawa K \& Matsukura S 2001 A role for ghrelin in the central regulation of feeding. Nature 409 194-198.
O'Dowd BF, Scheideler MA, Nguyen T, Cheng R, Rasmussen JS, Marchese A, Zastawny R, Heng HH, Tsui LC \& Shi X 1995 The cloning and chromosomal mapping of two novel human opioid-somatostatin-like receptor genes, GPR7 and GPR8, expressed in discrete areas of the brain. Genomics 28 84-91.

Polak JM, Bloom SR, Rayford PL, Pearse AG, Buchan AM \& Thompson JC 1975a Identification of cholecystokinin-secreting cells. Lancet 7943 1016-1018.

Polak JM, Pearse AG, Grimelius L \& Bloom SR 1975 b Growth-hormone release-inhibiting hormone in gastrointestinal and pancreatic D cells. Lancet 7918 1220-1222.

Sakurai T, Amemiya A, Ishii M, Matsuzaki I, Chemelli RM, Tanaka H, Williams SC, Richardson JA, Kozlowski GP, Wilson S, Arch JRS, Buckingham RE, Haynes AC, Carr SA, Annan RS, McNulty DE, Liu W-S, Terrett JA, Elshourbagy NA Bergsma DJ \&

Yanagisawa M 1998 Orexins and orexin receptors: a family of hypothalamic neuropeptides and $\mathrm{G}$ protein-coupled receptors that regulate feeding behavior. Cell 92 573-585.

Schwartz MW, Woods SC, Porte D Jr, Seeley RJ \& Baskin DG 2000 Central nervous system control of food intake. Nature $\mathbf{4 0 4}$ 661-667.

Shimomura Y, Harada M, Goto M, Sugo T, Matsumoto Y, Abe M, Watanabe T, Asami T, Kitada C, Mori M, Onda H \& Fujino M 2002 Identification of neuropeptide $\mathrm{W}$ as the endogenous ligand for orphan G-protein-coupled receptors GPR7 and GPR8. Journal of Biological Chemistry 277 35826-35832.

Solcia E, Capella C, Buffa R, Usellini L, Fiocca R \& Sessa F 1987 Endocrine cells of the digestive system. In Physiology of the Gastrointestinal Tract, edn 3, vol 1, pp 111-130. Ed LR Johnson. New York: Raven Press.

Spiegelman BM \& Flier JS 2001 Obesity and the regulation of energy balance. Cell 104 531-543.

Sundler F \& Håkanson R 1991 Gastric endocrine cells typing at the light microscopic level. In The Stomach as an Endocrine Organ, pp 9-26. Eds R Håkanson \& F Sundler. Amsterdam: Elsevier.

Suzuki N, Matsumoto H, Kitada C, Masaki T \& Fujino M 1989 A sensitive sandwich-enzyme immunoassay for human endothelin. Journal of Immunological Methods 118 245-250.

Tanaka H, Yoshida T, Miyamoto N, Motoike T, Kurosu H, Shibata K, Yamanaka A, Williams SC, Richardson JA, Tsujino N, Garry MG, Lerner MR, King DS, O'Dowd BF, Sakurai T \& Yanagisawa M 2003 Characterization of a family of endogenous neuropeptide ligands for the G protein-coupled receptors GPR7 and GPR8. PNAS 100 6251-6256.

Walsh JH 1994 Gastrointestinal hormones. In Physiology of the Gastrointestinal Tract, edn 3, vol 1, pp 1-128. Ed LR Johnson. New York: Raven Press.

Wren AM, Small CJ, Abbott CR, Jethwa PH, Kennedy AR, Murphy KG, Stanley SA, Zollner AN, Ghatei MA \& Bloom SR 2002 Hypothalamic actions of neuromedin U. Endocrinology 143 $4227-4234$.

Received in final form 30 August 2005 Accepted 30 September 2005 